\title{
PES CAVUS AND CLAW TOES DEFORMITY IN PATIENTS WITH SPINAL CORD INJURY AND MULTIPLE SCLEROSIS
}

\author{
By Manuel Rivera-Dominguez, M.D., M. DiBenedetto, M.D., J. H. Frisbie, M.D. \\ and A. B. Rossier, M.D. \\ Spinal Cord Injury and Rehabilitation Medicine Services, West Roxbury Veterans Adminis- \\ tration Hospital, I 400 V.F.W. Parkway, Boston, Mass. O2I 32, Departments of Orthopaedic \\ Surgery and Medicine, Harvard Medical School, U.S.A.
}

Abstract. Patients with spinal cord injury or multiple sclerosis were surveyed for the presence of extreme foot deformities and spasticity. Pes cavus and claw toes were found in eight of 80 spastic spinal cord injury and two of 20 multiple sclerosis patients. Pes cavus and claw toes were not found in 29 flaccid spinal cord injury patients.

Pes cavus and claw toes were associated with flexor reflexes which could be elicited by pin prick proximal to the knee, suggesting extreme spasticity-and by low excitatory thresholds for the anterior tibialis as indicated electromyographically.

Complications of severe spasticity associated with spinal cord injury and multiple sclerosis include pes cavus and claw toes, mediated in part by spasms of the anterior tibialis.

Key words: Spinal cord injuries; Multiple sclerosis; Spasticity; Diffuse excitatory skin areas; Anterior tibialis; Pes cavus; Claw toes.

\section{Introduction}

Pes CAvus, also known as pes arcuatus or hollow foot, is characterised by an exaggerated, longitudinal arch with the apex at the navicular-cuneiform joint. A shortened plantar fascia complicates and reinforces the deformity. Claw toes are characterised by hyperextension at the metatarsal-phalangeal joints and flexion of the interphalangeal joints (Ingram, I97I). Pes cavus and claw toes are different from pes equinus, a more common manifestation of spasticity which precedes those deformities.

Spasticity and foot deformities are associated with spinal cord injury and multiple sclerosis (Giannestras, I953; Ingram, I97 I). It was our purpose to study the prevalence of the foot deformities pes cavus and claw toes found in spastic spinal cord injury and multiple sclerosis patients and to discuss the pathogenesis of these foot deformities with the help of electromyography.

\section{Selection of Patients}

\section{Materials and Methods}

Patients admitted to the Spinal Cord Injury and Rehabilitation Services at the West Roxbury Veterans Administration Hospital were selected at random and assessed for the presence or absence of spasticity, pes cavus, and claw toes.

\section{Spasticity}

The diagnosis of spasticity was made by the presence of resistance to passive range of motion, accentuated deep tendon reflexes, and the presence of a flexor 
reflex, quantitated by the level of excitatory skin areas (Rivera-Dominguez et al., 1979).

\section{Foot Deformity}

The diagnosis of pes cavus was made by the observation of an exceptionally high arch; agreement in this observation between the primary investigator, M. R., and a second physician; and a negative history of high arch prior to spinal cord injury. The diagnosis of claw toes was based on hyperextension at the metatarsalphalangeal joints and hyperflexion of the interphangeal joints. Mobility of all foot joints was also assessed.

\section{Electromyography}

Electromyography was performed in patients with foot deformity by placing coaxial needle electrodes in the anterior tibial, posterior tibial, extensor hallucis longus, gastrocnemius, rectus femoris, and medial hamstring muscles and recording motor unit activities simultaneously through six amplifiers ( $\mathrm{Teca} \mathrm{T}_{4}{ }^{1}$ ), triggering a 6-channel 5-I34 recording oscillograph. ${ }^{2}$ These recordings were carried out before and after skin stimulation. Activation of motoneurons was by temporal and spatial recruitment. None of the potential and amplitudes exceeded $3 \mathrm{mV}$. The stimulus consisted of 3-5 pin pricks per second, manually applied from the skin of the lower abdominal wall distally to the lower extremities. Ipsilateral flexion of the lower extremity and occasional contralateral contractions of flexors or extensors were observed.

\section{Prevalence of Foot Deformity}

\section{Results}

Eighty spinal cord injury patients aged 25 to 68 (mean 43) were surveyed. The duration of the spinal cord lesion was 2 months to 17 years. Fifty-one of these patients had upper motor neuron lesions and were spastic; all but one had mobile equinus foot deformity. Eight of these 5 I patients had pes cavus or claw toes or both deformities in addition to equinus deformity. The levels of injury in these eight patients were cervical in two (one incomplete) and dorsal in six (one incomplete). Conversely, none of the 29 flaccid patients had pes cavus or claw toes deformity.

Twenty multiple sclerosis patients aged 33 to 48 years (mean 38 ) were also surveyed. The duration of the neurological deficit varied from 3 to 17 years. All patients were spastic and had equinus deformity. One of these patients also had pes cavus and another had claw toes and pes cavus.

Of these eight spinal cord injury and two multiple sclerosis patients with extreme foot deformities, five had pes cavus, one had claw toes, and four had both pes cavus and claw toes.

\section{Extent of Excitatory Skin Areas and Foot Deformity}

The extremes of foot deformity were found in the patients with more extensive excitatory skin areas. All ten patients with pes cavus or claw toes had excitatory skin areas proximal to the knee but all spastic patients without these extremes of foot deformity had excitatory skin areas confined distal to the knee (Fig. I).

\footnotetext{
${ }^{1}$ Teca Corp., White Plains, N.Y.

${ }^{2}$ Bell and Howell, Needham, Ma.
} 


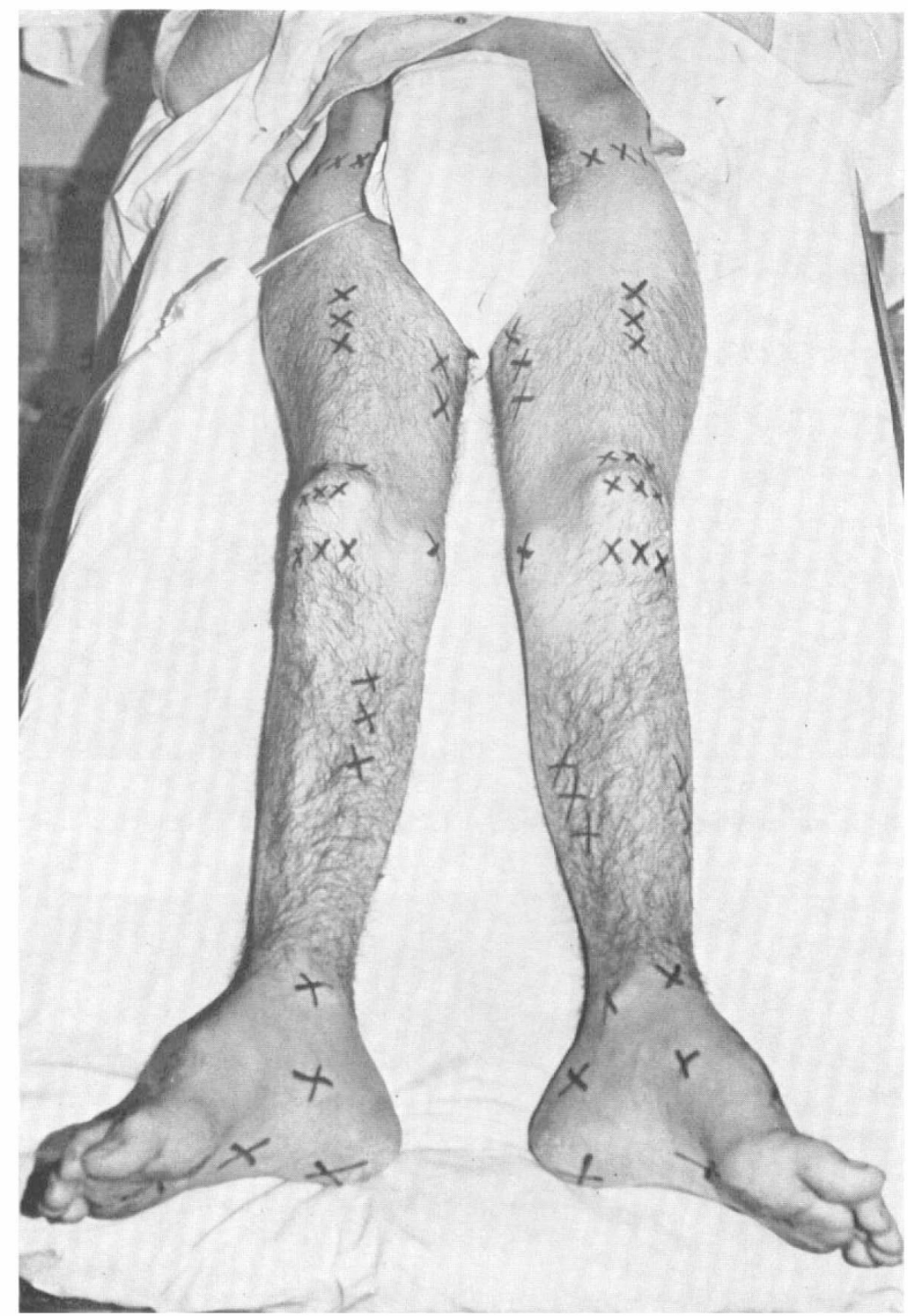

FIG. I

Excitatory skin areas marked by $\mathrm{Xs}$ in 20 -year-old patient RL with complete spastic paraplegia $T_{4}-T_{5} 2 \frac{1}{2}$ months after injury. The stimulus was pin prick; the response ipsilateral withdrawal of the entire lower limb.

\section{Medical Complications}

Time and medical complications accentuated spasticity and pre-existing foot deformity (Figs 2 and 3).

\section{Electromyographic Observations}

Stimulation of excitatory skin areas produced spasms in specific muscles according to the frequency and duration of the stimulus (Fig. 4). The order of 


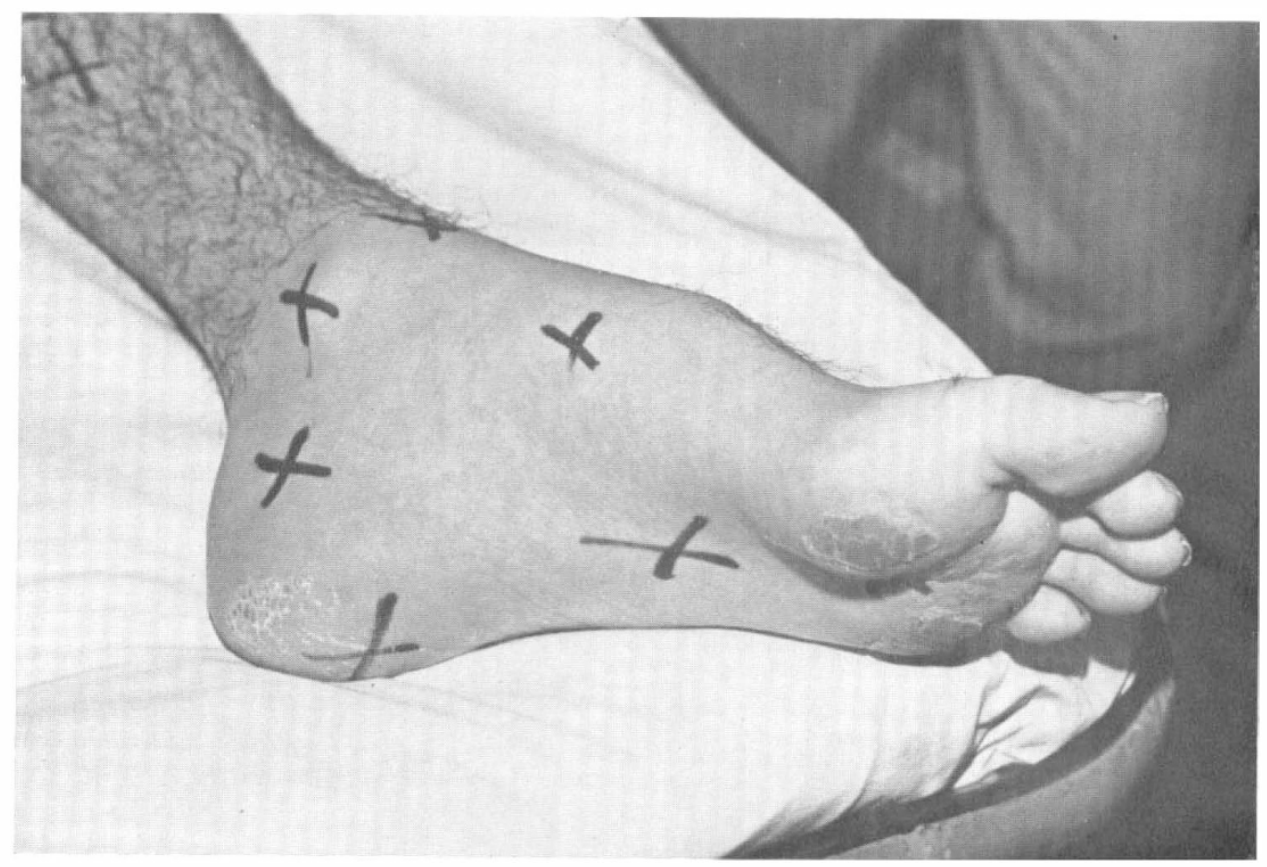

FIG. 2

Medial aspect, right foot of patient RL $2 \frac{1}{2}$ months post spinal cord injury.

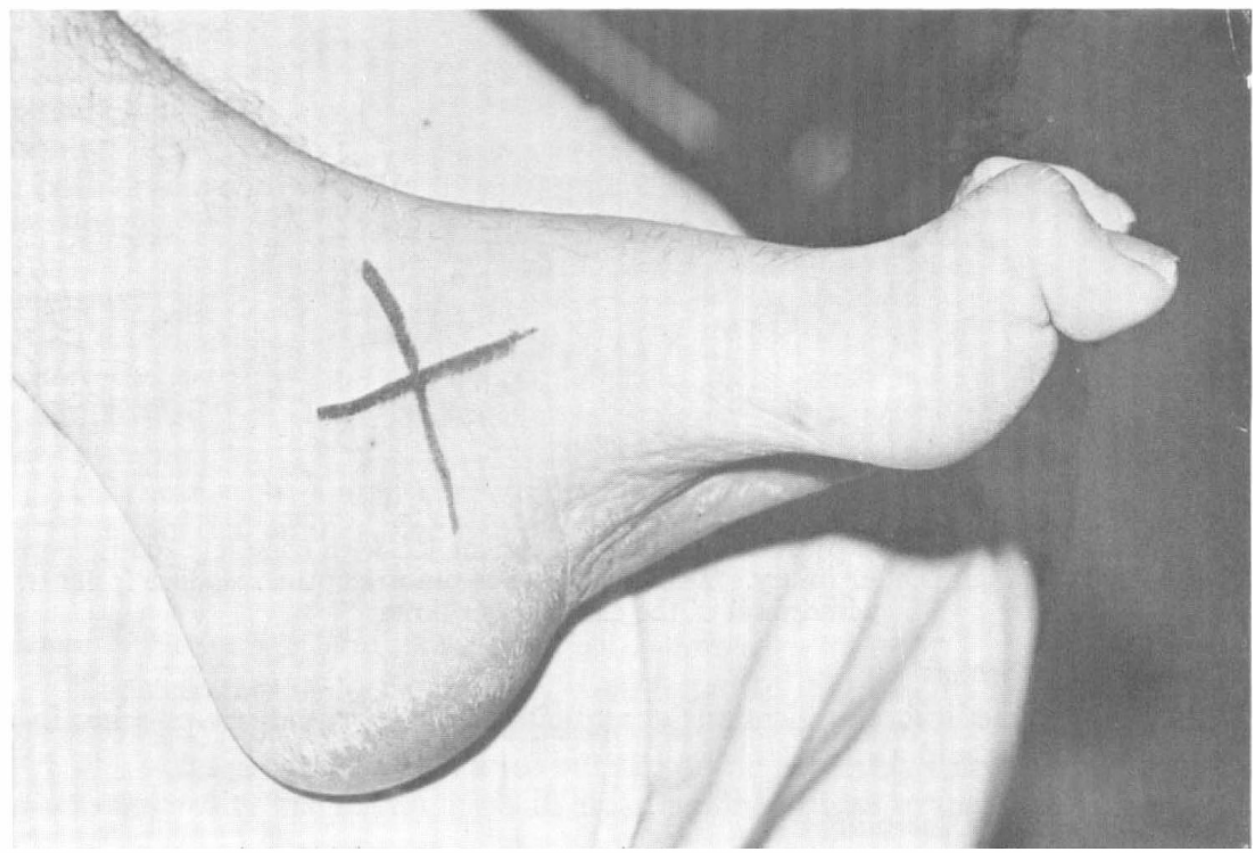

FIG. 3

Same foot as shown in Fig. 2, $6 \frac{1}{2}$ months after injury and after the development of paronychia in the right great toe. 


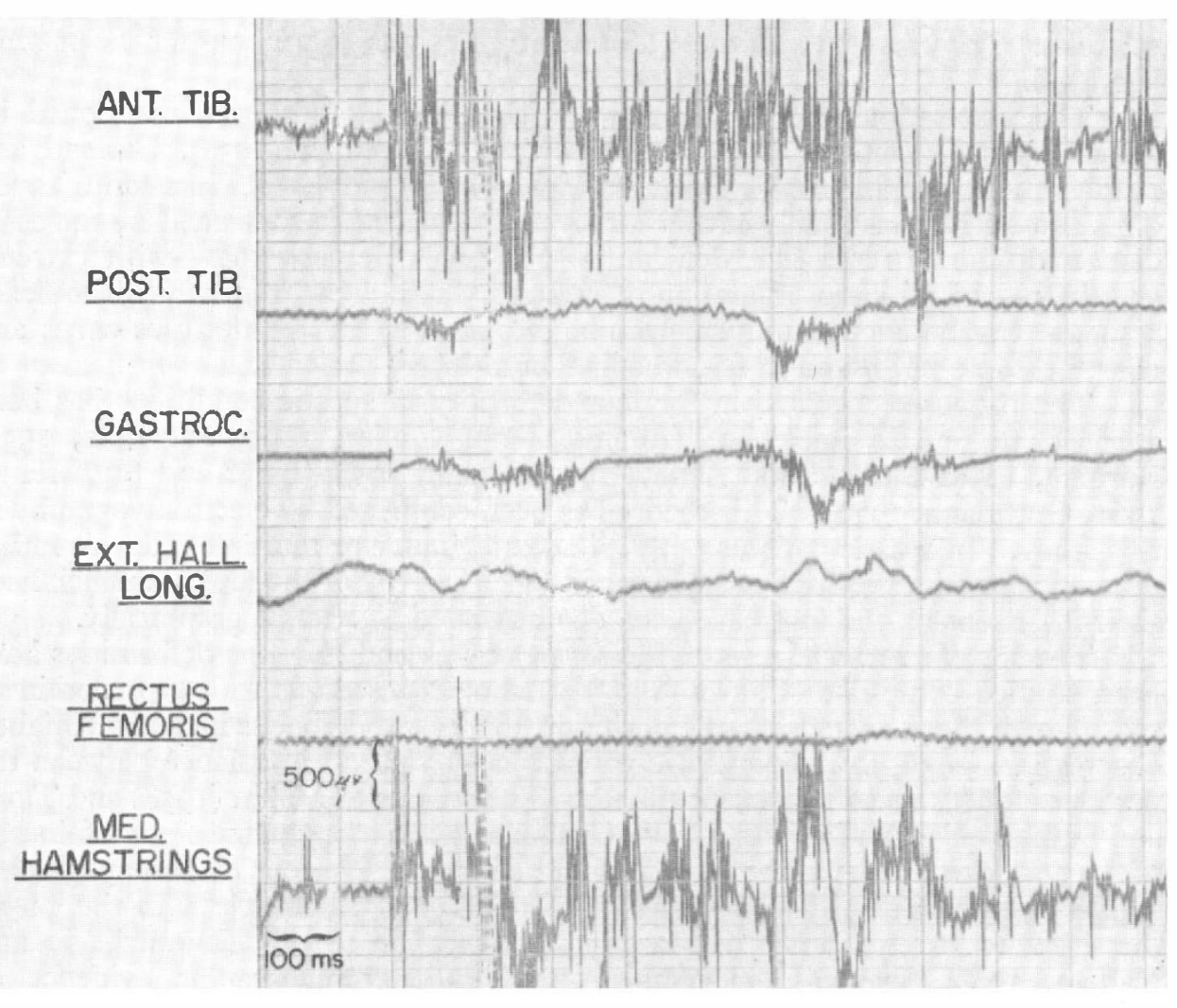

FIG. 4

Electromyography during stimulation of an excitatory skin area of patient RL $2 \frac{1}{2}$ months after injury.

recruitment was the anterior tibialis, the hamstrings, the gastrocnemius, the posterior tibialis, the extensor hallucis longus, and the rectus femoris. This hierarchy of muscle recruitment was consistent in the ten patients studied with foot deformity. In any given patient this order did not vary for any of the skin zones sensitive to stimulation. When the stimulus was removed the evoked recruitment, whether maximal or minimal, persisted for I-2 sec at the same level of discharge activity before diminishing as determined electromyographically. There was no rebound activity. Reactivation of spasms by stimulation of previously excited skin areas showed facilitation.

Although eight of the ten foot deformity patients displayed a Babinski sign none showed a predominant electromyographic activity of the extensor hallucis longus at 'rest'.

\section{Discussion}

The extremes of foot deformity, pes cavus and claw toes have been described in spastic spinocerebellar atrophy (Plowright, 1928; Makin, 1958; Tyrer and Sutherland, 196I), hereditary spastic paraplegia (Garland and Astley, I950), and myelomeningocele (Sharrard and Grosfield, I968; Sharrard, 1973). We have also I6/4 D 
found these foot deformities in patients with spastic spinal cord injury and multiple sclerosis. The prevalence of these foot deformities was io per cent for the patients surveyed.

The association of foot deformity with spasticity has been mentioned by Adams (1873), Collier (1899), Saunders (1935), Burman (1938), Garland and Astley (1950), Makin (1958), Tyrer and Sutherland (I96I), and Guttmann (1970). This association was found in this survey and was further confirmed by the association of the extreme foot deformity-pes cavus or claw toes-with extreme spasticity-the proximal migration of excitatory skin areas from which the flexor response can be elicited (Rivera-Dominguez et al.). In addition pes cavus and claw toes were not found in flaccid spinal cord injury patients.

The proposed mechanism for foot deformity in spastic conditions has been ascribed to muscle imbalance (Adams, I873; Collier, I899; Saunders, I935; Burman, I938; Garland and Astley, I950; Makin, 1958; Tyrer and Sutherland, I96I, Guttmann, I970). This theory has been confirmed by electromyography in this study. In spastic patients with spinal cord injury or multiple sclerosis rather dramatic quantitative differences in the induced activity of the muscles which have their insertions on the foot have been demonstrated electromyographically.

The specific muscles responsible for pes cavus and claw toe deformities have been studied clinically. Collier (I899) attributed pes cavus to the predominant spasticity of the toe extensors, the posterior tibialis and peroneus longus. Knight's observation (1956) in poliomyelitic patients suggested an imbalance between the peroneus longus and the anterior tibialis. The studies of Makin (1958) and Tyrer and Sutherland (I96I) in spastic spinocerebellar atrophy suggested a predominance of the posterior tibialis as the cause of foot deformity. Previous electromyographic studies in spastic disorders consistently mention that the muscle with the lowest threshold to exteroceptive response is the anterior tibialis (Dimitrijevic and Nathan, I968; Shahani and Young, 197I). Electromyographic evidence of spasticity in individual muscles in this study pointed to a predominance of the anterior tibialis. Because of the contribution of flexor and extensor digitorum longus to the development of claw toes deformity, studies of these muscles would be of interest. However, it is almost impossible to reliably place the needle electrodes in these muscles in patients unable to perform any specific muscle functions due to paralysis.

Pes cavus can be explained by the predominant activity of the anterior tibialis because of its insertion into the medial and plantar surface of the first cuneiform and the base of the first metatarsal. The pull of the anterior tibialis with its insertion at the apex of the arch of the foot in addition to the pull from muscles creating the equinus deformity appears to create pes cavus.

An additional factor in the development of pes cavus may be the reflex activity of the extensor hallucis longus. Dorsiflexion of the great toe by the extensor hallucis longus, as observed in the Babinski sign, approximates the head of the metatarsal toward the heel, thereby heightening the arch of the foot (Hicks, I953).

Conceptually, pes cavus and claw toes develop after the onset of extreme spasticity, as evidenced by the enlargement of excitatory skin areas and by electromyographic detection of a low excitatory threshold in muscles inserting on the foot, predominantly the anterior tibialis.

Practical aspects of the development of pes cavus and claw toes are the difficulty in fitting shoes and the susceptibility to pressure sores on bony prominences, especially in feet deprived of sensation. The clinician who recognises the hazards of pes cavus or claw toes in a spastic patient has an opportunity to prevent 
complications by removing remote irritating foci, treating spasticity pharmacologically, and fitting shoes appropriately.

\section{RÉSUMÉ}

Le problème des déformations marquées de pied et de spasticité est analysé chez 80 lésions médullaires traumatiques spastiques et 20 scléroses en plaques. Hujt des traumatisés médullaires et 2 des scléroses en plaques avaient un pied creux et des orteils en griffe, mais par contre aucune des 29 lésions médullaires traumatiques flasques.

Il existe une relation de cause à effet entre pied creux, orteils en griffe et réflexes en flexion déclenchables par un stimulus-piqure-appliqué en dessus du genou, suggérant d'une part une spasticité très marquée, et de l'autre, un bas seuil d'excitabilité du tibial antérieur démontré par l'électromyographie.

Dans les lésions médullaires traumatiques spastiques et les scléroses en plaques, pied creux et orteils en griffe sont l'expression d'une spasticité marquée, et plus particulièrement des spasmes du tibial antérieur.

\section{ZUSAMMENFASSUNG}

Ein Überblick Rückenmarkverletzter und von Patienten mit Multipler Sklerose wurde unternommen, um die Gegenwart von Spastizität und Fussmissbildungen festzustellen, welche dann electromyographisch untersucht wurden. Hohlfuss und Krallenzehen wurden in 8 (acht) aus 80 (achtzig) spastischen Rückenmarkverletzten und in 2 (zwei) von den Multiple Sklerose Patienten gefunden. Keiner der 29 (neun and zwanzig) schlaffen Querschnitts gelähmten wiesen diese Missbildungen auf.

Hohlfuss und Krallenzehen waren verbunden mit der Entwicklung von Spastizitätangedeutet durch den Fortschritt der erregbaren Hautbezirke über das Knie-und durch eine elektromyographisch bewiesene niedrige Erregbarkeitsschwelle des Musculus Tibialis Anterior.

Fussmissbildung ist ein Zeichen der Spastizität verbunden mit Rückenmarkverletzung und Multipler Sklerose. Spastizität des Musculus Tibialis Anterior führt zu Hohlfuss und ist dann oftmals kompliziert durch Krallenzehen.

\section{REFERENCES}

Adams, W. (1873). Club foot, it Causes, Pathology and Treatment, 2nd ed., p. 94. Churchill, London.

BuRMAN, M. S. (1938). Spastic intrinsic muscle imbalance of the foot. F. Bone foint Surg., 20, I $45-\mathrm{I} 48$.

Collier, J. (I899). An investigation upon the plantar reflex, with reference to the significance of its variations under pathological conditions, including an enquiry into this aetiology of acquired pes cavus. Brain, 22, 7I-99.

Dimitrijevic, M. R. \& NATHAN, P. W. (I968). Studies of spasticity in man. 3. Analysis of reflex activity evoked by noxious cutaneous stimulation. Brain, 91, 349-368.

Garland, H. G. \& AstLEY, C. E. (I950). Hereditary spastic paraplegia with amyotrophy and pes cavus. F. Neurol. Neurosurg. Psychiat., 13, 130-133.

Giannestras, N. J. (I953). Dural and intradural compression as a cause of club foot. Clin. Orthop., I, 28-32.

Guttmann, L. (1970). Spinal shock and reflex behaviour in man. Paraplegia, 8, I00-I Io.

Hicks, J. H. (1953). The mechanisms of the foot. I. The joints. F. Anat., 87, 345-357.

IngRAM, A. J. (I97I). Anterior poliomyelitis. In Campbell's Operative Orthopaedics, A. H. Crenshaw, ed. Mosely, St. Louis, Mo. Vol. 2, p. I535.

Makin, M. (I958). The surgical management of Friedreich's ataxia. Ann. Roy. Coll. Surg. Engl., 22, I-IO.

Plowright, O. (1928). Familial claw foot with absent tendon-jerks and cerebellar disease. Guy's Hosp. Rep., 8, 314-319.

Rivera-Dominguez, M., Frisbie, J. H., DiBenedetto, M. \& Rossier, A. B. (i979). Quantitated flexor response in acute spinal cord injury patients. Paraplegia, in press.

SAUNDERS, J. H. (1935). Etiology and treatment of clawfoot. Arch. Surg., 30, I79-I98.

Shahani, B. \& Young, R. R. (197I). Human flexor reflexes. F. Neurol. Neurosurg. Psychiat., 34, 616-627. 
Sharrard, W. J. W. (1973). The orthopaedic surgery of spina bifida. Clin. Orthop., 92, I95-2 I3.

SHARRARD, W. J. W. \& GRosFIELD, I. (I968). The management of deformity and paralysis of the foot in myelomeningocele. F. Bone foint Surg., 50B, 456-465.

Tyrer, J. H. \& SutherLAND, J. M. (I96I). The primary spino-cerebellar atrophies and their associated defects, with a study of the foot deformity. Brain, 84, 289-299. 